\title{
The Rwanda National Blindness Survey: Trends and use of the evidence to change practice and policy

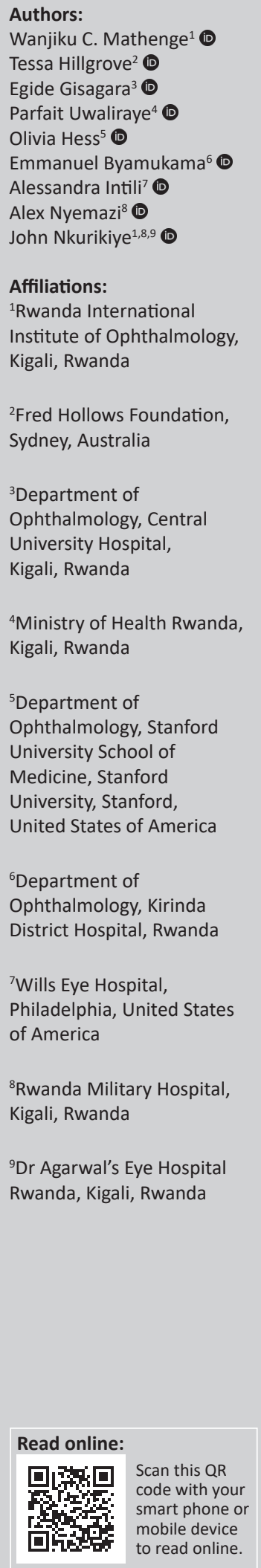

Background: In order to gather evidence to guide eye care policy changes in Rwanda, a national population-based blindness and visual impairment survey was undertaken in 2015.

Aim: To influence and direct policy changes using blindness survey findings.

Setting: Nationwide sampling.

Methods: Standard Rapid Assessment of Avoidable Blindness (RAAB) survey methodology was used across to examine 5065 (97.5\% response rate) people aged 50 years and older. This is a case report of how the government used the evidence from the survey.

Results: The age- and sex-adjusted prevalence of blindness was 1.1\% (0.7-1.4) of which 83.9\% was avoidable, with cataract being the major cause. The age- and sex-adjusted prevalence of visual impairment at the $6 / 18$ level is $4.4 \%$ (3.7-5.1), with refractive errors and cataract being the major causes. The prevalence of all refractive errors was $4.3 \%$, the majority of which was uncorrected. The cataract surgical coverage (CSC) was $68.4 \%$, with $45.4 \%$ of surgeries performed at the secondary level. Difficulty in reaching surgical facilities (33.3\%) was the main barrier to surgery. These results informed policy changes aimed towards an increase in the number of cataract surgeons, the volume of cataract surgery performed and broader spectacle provision.

Conclusion: The prevalence of blindness in Rwanda is low compared to the previous estimates, although a considerable proportion is avoidable and the majority of refractive errors were uncorrected. The CSC and surgical outcomes are improving. The government, informed by this evidence, has introduced targeted initiatives to improve eye-care delivery in Rwanda.

Keywords: RAAB; policy change; visual impairment; Rwanda; blindness; evidence.

\section{Introduction}

Worldwide, an estimated 253 million people have visual impairment or blindness with presenting visual acuity (PVA) $<6 / 18$, and this figure may rise to 700 million by 2050 . Almost 32.4 million of them are blind (PVA < 3/60). ${ }^{1}$ In 1999, the World Health Organization (WHO) and the International Agency for the Prevention of Blindness (IAPB) launched the global initiative known as 'VISION 2020: The Right to Sight', which calls for the elimination of avoidable blindness by 2020. ${ }^{2}$ Three years later, the initiative was launched in Rwanda. At the time (2002), little was known about the prevalence and causes of blindness in the region. With the development of the Rapid Assessment of Cataract Surgical Services and later the Rapid Assessment of Avoidable Blindness (RAAB), ${ }^{3}$ a standard validated, simple, affordable and rapid survey methodology ${ }^{4}$ could be applied in different scenarios, including those with limited resources, and trends could be tracked by repeating the surveys at regular intervals. The RAAB survey is used to collect reliable estimates of the magnitude and causes of blindness at district or regional level or even national level. ${ }^{5}$ The RAAB only includes the over-50-year age group, where the prevalence of blindness and visual impairment is the highest, ${ }^{3}$ so that required sample sizes are minimised. The RAAB also uses relatively straightforward sampling and examination techniques, reducing time and cost.

\footnotetext{
Corresponding author: Wanjiku Mathenge, ciku@email.com
}

Dates: Received: 07 May 2020 | Accepted: 04 Apr. 2021 | Published: 15 July 2021

How to cite this article: Mathenge WC, Hillgrove T, Gisagara E, et al. The Rwanda National Blindness Survey: Trends and use of the evidence to change practice and policy. Afr Vision Eye Health. 2021;80(1), a576. https://doi.org/10.4102/aveh.v80i1.576

Copyright: (C) 2021. The Author(s). Licensee: AOSIS. This work is licensed under the Creative Commons Attribution License. 
The information generated from the RAAB survey can be used by policymakers and planners to identify priorities and provide resources for eye care in a country. Knowledge is the world's most valuable resource; it should not be wasted but rather used as a resource for effective healthcare policies. ${ }^{6}$ This is especially important in low-resource settings, such as Rwanda, where approximately $80 \%$ of the blindness and visual impairment is from conditions that could have been prevented or managed to restore vision. ${ }^{7}$ Indeed, one of the key objectives of the RAAB approach is described as provision of baseline data for planning of eye-care services and to monitor and evaluate ongoing programmes. ${ }^{8}$

Several surveys of blindness in the East Africa region have shown a low prevalence of blindness. For example, RAAB in Northern Burundi (2012) found an adjusted blindness prevalence of $1.2(0.8-1.5),{ }^{9}$ and in Hoima, a district in the western part of Uganda (2013), found a prevalence of 2.0 $(1.5-2.4){ }^{10}$ The first survey of blindness in Rwanda was conducted in 2006 and covered the Western province. ${ }^{11}$ The study reported a sex- and age-adjusted prevalence of blindness of $1.6 \%(1.0 \%-2.2 \%)$, severe visual impairment of $1.1 \%(0.7 \%-1.6 \%)$ and moderate visual impairment of $4.9 \%$ $(3.8 \%-6.0 \%)$. The majority of bilateral blindness $(65 \%)$ was because of cataract; and overall, the vast majority of cases of blindness $(80.0 \%)$, severe visual impairment $(67.9 \%)$ and visual impairment $(87.2 \%)$ were avoidable (i.e. because of cataract, refractive error, aphakia, trachoma or corneal scar). The results from that survey have since been extrapolated and used to guide planning and prioritisation of the several eye health initiatives that have been initiated across the country. Nine years later, a need was felt to carry out a more comprehensive survey covering the whole country for monitoring progress and trends in the care programme over the ensuing decade. Indeed, other researchers have noted that many more opportunities are available to use this resource, such as to estimate the need for low-vision services, trends over time or between regions or to compare levels of indicators such as poor surgical outcomes.

The aim of this second RAAB study in Rwanda was not only to estimate the prevalence and causes of blindness and visual impairment amongst people aged $\geq 50$ years in the Republic of Rwanda but also to investigate any changes or trends when compared with the earlier RAAB study (the secondary aim). The study was supported by the Fred Hollows Foundation and the Ministry of Health (MOH).

\section{Methods for the Rapid Assessment of Avoidable Blindness}

This research followed the standard RAAB methodology.

\section{Sample size}

The sample size, based on a cluster random sampling approach, was calculated using the RAAB software (version 5). Census data from 2012 were used to estimate the proportion of the population aged 50 years and older, ${ }^{12}$ and an assumed prevalence of severe visual impairment and blindness for those aged 50 years and older was estimated at $3.0 \%$ based on the results of the 2006 Western province RAAB. ${ }^{11}$ Based on these inputs, a minimum sample size of 5161 persons was calculated (104 clusters of 50), assuming an estimate precision of $20 \%$, a $95 \%$ confidence level and a non-response rate of $10 \%$.

\section{Sampling frame}

For the first stage of sampling, clusters were selected from across the entire country based on 2012 census data, ${ }^{12}$ with the probability of a cluster's selection proportional to population size. For the second stage of sampling, households within the clusters were selected based on compact segment sampling. Each cluster area was divided into a number of segments, known locally as 'mudugudu', which are local administrative areas with well-defined boundaries. Maps were drawn to identify the mudugudu within a given cluster, and one was chosen at random by drawing lots. Starting at the edge of the segment, all households in the chosen mudugudu were visited in the sample sequentially until 50 people aged 50 years and older had been identified. Eligible participants were those aged 50 years or older and who had lived in the household for at least three months of the year. If the mudugudu did not include 50 people aged 50 years and above, then another segment was chosen at random and sampling continued until the required cluster size of 50 was achieved. If an eligible household member was not available, and they could not be visited within the locale, and information was collected from relatives or neighbours.

\section{Ophthalmic examination}

All consenting participants had PVA tested in each eye using a modified Snellen's E chart at $6 \mathrm{~m}$. Pinhole vision was tested for any eye with VA of less than 6/18. All participants were examined for lens opacity or aphakia/ pseudophakia. All participants with vision less than $6 / 18$ in one or both eyes received dilating drops and were examined further by an ophthalmologist to determine the cause of visual impairment in each eye. The WHO guidelines were used to determine the causes of visual impairment for each eye and for the individual. ${ }^{13}$ Participants with cataracts were asked for the reason they had not pursued cataract surgery, whilst those who had undergone cataract surgery were asked to provide the location of surgery. Causes of vision less than 6/18 in the operated eye were determined. Participants who needed further assessment and treatment were referred to the nearest appropriate health facility whilst minor conditions were treated on the spot.

Close or proximal VA is not included in the RAAB examination; however, the survey included a question asking whether people had ever had any problems with their eyes. This figure, together with the proportion who used near vision correction, was used to calculate the proportion of people with uncorrected presbyopia. 
The village leader was contacted two days prior to data collection in the selected mudugudu and briefed on the purpose of the RAAB. The village leader then arranged for a local guide to support the study team. Each study team consisted of an ophthalmologist, an ophthalmic technician and a driver. The teams utilised modified Snellen's E charts, 6-m ropes, pin holes, pen torches and direct ophthalmoscopes to conduct the examinations.

\section{Data management}

All data were recorded in simple one-page survey forms, which were daily cross-checked in the field to identify and correct mistakes. Double data entry was performed each day using the RAAB version 5 software, which has an integrated consistency check. Data analysis was undertaken using the RAAB software, with additional analysis performed using Stata version 13.

\section{Training and standardisation}

There were four study teams utilised in this RAAB, who simultaneously collected the data. All four teams received a 4-day training course by a certified RAAB trainer immediately before the survey. All field staff members were thoroughly trained to ensure uniformity of procedure in identifying eligible participants, assessing VA and examining the ocular lens. During training, the interobserver variability was assessed for vision, lens assessment and causes of visual impairment to ensure that examiners have at least $70 \%$ agreement. Each team was given standardised instructions on definitions, the method of selection of the participants, examination protocol and methods to obtain and record the data for their reference.

\section{Ethical considerations}

The study adhered to the tenets of the Declaration of Helsinki. The study visa was issued by the National Institute of Statistics of Rwanda and ethics approval was given by the Rwanda National Ethics Committee (0624/2015/10/ NISR). The survey secured ethical approval from the Rwanda Health Research Committee (RHRC) and the Rwanda National Ethics Committee and approval from the Ministry of Health (MOH). The purpose and procedures of the study were explained verbally by study teams and through a written patient information sheet in the local language, Kinyarwanda, with verbal and written consent obtained prior to participation. As this was a national survey, it was imperative to obtain a visa (document of approval) to conduct the survey, which was provided by the National Institute of Statistics of Rwanda. All information of participants was confidentially handled. People identified with ocular conditions requiring treatment or follow-up were referred to the nearest ophthalmic or medical centres as appropriate.

Information in the case study was obtained from the Director General of Planning at the $\mathrm{MOH}$.

\section{Results}

The response rate was high (97.5\%), with a total of 5065 participants out of the 5194 eligible participants examined. Ninety-one people were not available, 12 refused examination and 26 could not be examined because of other disabilities.

The age and gender composition of the sample was similar to that of the Rwandan population, with remarkable reduction in the number of men vis-à-vis women above the age of 35 years across the country (see Table 1 ).

The unadjusted blindness prevalence was 1.2\% (95\% confidence interval [CI] 0.9-1.6), with $1.5 \%$ in men and $1.1 \%$ in women (see Tables 2 and 3). However, when adjusted for age and sex, the blindness prevalence was 1.1\% (CI 0.7-1.4), with men having a prevalence of $1.3 \%(0.7-1.9)$ and women having a prevalence of $0.9 \%(0.5-1.3)$. The sex- and age-adjusted prevalence of all visual impairment was $4.4 \%$ (3.7-5.1). No significant difference was observed in the prevalence of blindness and visual impairment in men and women. The likelihood of blindness significantly increased with age, with just $0.2 \%(0.0-0.3)$ of the sample blind in the $50-59$ years age group but $6.5 \%(4.0-8.7)$ blind in the $80+$ years age group.

\section{Causes of blindness and visual impairment}

The major causes of blindness were untreated cataract $(56.5 \%)$, glaucoma $(14.5 \%)$ and other posterior segment causes $(9.7 \%)$. Corneal opacities (three cases), including one

TABLE 1: Age and gender distribution of people examined in the sample.

\begin{tabular}{lcccccccc}
\hline Age (years) & \multicolumn{2}{c}{ Males $(\boldsymbol{n}=\mathbf{1 9 7 6})$} & & \multicolumn{2}{c}{ Females $(\boldsymbol{n}=\mathbf{3 0 8 9})$} & & \multicolumn{2}{c}{ Total $(\boldsymbol{n}=\mathbf{5 0 6 5})$} \\
\cline { 2 - 3 } & $\boldsymbol{n}$ & $\mathbf{\%}$ & & $\boldsymbol{n}$ & $\mathbf{\%}$ & & $\boldsymbol{n}$ & $\boldsymbol{\%}$ \\
\hline $50-59$ & 898 & 45.4 & & 1354 & 43.8 & & 2252 & 44.5 \\
$60-69$ & 626 & 31.7 & & 944 & 30.6 & & 1570 & 31.0 \\
$70-79$ & 281 & 14.2 & & 486 & 15.7 & & 767 & 15.1 \\
$80+$ & 171 & 8.7 & & 305 & 9.9 & & 476 & 9.4 \\
\hline
\end{tabular}

TABLE 2: Sample prevalence (unadjusted) and population adjusted results for all causes of blindness.

\begin{tabular}{|c|c|c|c|c|c|c|c|c|c|}
\hline \multirow[t]{2}{*}{ Sample prevalence } & \multicolumn{3}{|c|}{ Males } & \multicolumn{3}{|c|}{ Females } & \multicolumn{3}{|c|}{ Total } \\
\hline & $n$ & $\%$ & $95 \% \mathrm{Cl}$ & $n$ & $\%$ & $95 \% \mathrm{Cl}$ & $n$ & $\%$ & $95 \% \mathrm{Cl}$ \\
\hline Blindness (VA < $3 / 60$ ) & 29 & 1.5 & $0.9-2.0$ & 33 & 1.1 & $0.7-1.4$ & 62 & 1.2 & $0.9-1.5$ \\
\hline SVI $(V A<6 / 60-V A>3 / 60)$ & 16 & 0.8 & $0.4-1.2$ & 25 & 0.8 & $0.5-1.1$ & 41 & 0.8 & $0.6-1.1$ \\
\hline MVI $(\mathrm{VA}<6 / 18->6 / 60)$ & 42 & 2.1 & $1.5-2.7$ & 107 & 3.5 & $2.7-4.2$ & 149 & 2.9 & $2.4-3.5$ \\
\hline $\begin{array}{l}\text { All visual impairment and } \\
\text { blindness }(\text { VA }<6 / 18)\end{array}$ & 87 & 4.4 & $3.4-5.4$ & 165 & 5.3 & $4.5-6.2$ & 252 & 5.0 & $4.3-5.7$ \\
\hline
\end{tabular}

Note: visual acuity $<3 / 60$, severe visual impairment-visual acuity $<6 / 60$ and moderate visual impairment-visual acuity $<6 / 18$, with available correction.

$\mathrm{Cl}$, confidence interval, VA, visual acuity; SVI, severe visual impairment; $\mathrm{MVI}$, moderate visual impairment. 
case of trachomatous corneal opacity, accounted for $4.8 \%$ of all blindness. Cataract and refractive errors are the major causes of severe as well as moderate visual impairment, followed by age-related macular degeneration. The major cause of moderate visual impairment was refractive error, followed by cataract. In total, $83.9 \%$ of all blindness was avoidable, $61.3 \%$ of which was treatable (see Table 4 ).

\section{Cataract surgery}

The age- and sex-adjusted results for the country indicate the number of eyes in people aged 50 and above affected by cataract at each level of vision (see Table 5). An estimated backlog of 49464 Rwandan eyes had visually impairing cataract at the time of the survey, and 26874 of whom were blind.
The cataract surgical coverage (CSC) was high at $68.4 \%$ for blind persons and fell to $43.9 \%$ for cataract threshold of VA $<6 / 18$ cataract (see Table 6). Similar proportions of men and women had undergone cataract surgery. However, the effective cataract surgical coverage (eCSC) (Table 6) was lower at 54.4\%. The eCSC is calculated by considering CSC as well as the outcomes of surgery (shown in Table 7). Just over half of the cataract surgeries had been performed at referral hospitals (51\%), whilst $46 \%$ were completed at district hospitals, $3 \%$ by camp surgeons and $1 \%$ at private hospitals.

Of all the eyes operated, $70.9 \%$ resulted in a good outcome uncorrected (VA $>6 / 18$ ), and this rose to $80.1 \%$ with correction (see Table 7). However, $15.6 \%$ of eyes had a poor

TABLE 3: Sample prevalence (unadjusted) and population adjusted results for all causes of blindness.

\begin{tabular}{|c|c|c|c|c|c|c|c|c|c|}
\hline \multirow{2}{*}{$\begin{array}{l}\text { Sex- and age-adjusted } \\
\text { population prevalence }\end{array}$} & \multicolumn{3}{|c|}{ Males } & \multicolumn{3}{|c|}{ Females } & \multicolumn{3}{|c|}{ Total } \\
\hline & $\begin{array}{l}\text { Projected number } \\
\text { of people }(n)\end{array}$ & $\%$ & $95 \% \mathrm{Cl}$ & $\begin{array}{l}\text { Projected number } \\
\text { of people }(n)\end{array}$ & $\%$ & $95 \% \mathrm{Cl}$ & $\begin{array}{l}\text { Projected number } \\
\text { of people }(n)\end{array}$ & $\%$ & $95 \% \mathrm{Cl}$ \\
\hline Blindness - VA $<3 / 60$ & 5940 & 1.3 & $0.7-1.9$ & 5654 & 0.9 & $0.5-1.3$ & 11594 & 1.1 & $0.7-1.4$ \\
\hline SVI - (VA < 6/60->3/60) & 3328 & 0.7 & $0.3-1.1$ & 4582 & 0.7 & $0.4-1.0$ & 7910 & 0.7 & $0.5-1.0$ \\
\hline$M V I-(V A<6 / 18->6 / 60)$ & 9221 & 2.0 & $1.4-2.6$ & 19561 & 3.1 & $2.4-3.9$ & 28782 & 2.6 & $2.1-3.2$ \\
\hline $\begin{array}{l}\text { All visual impairment and } \\
\text { blindness (VA }<6 / 18 \text { ) }\end{array}$ & 18489 & 4.0 & $3.0-5.0$ & 29797 & 4.8 & $3.9-5.6$ & 48286 & 4.4 & $3.7-5.1$ \\
\hline
\end{tabular}

Note: visual acuity $<3 / 60$, severe visual impairment-visual acuity $<6 / 60$ and moderate visual impairment-visual acuity $<6 / 18$, with available correction

$\mathrm{Cl}$, confidence interval, VA, visual acuity; SVI, severe visual impairment; $\mathrm{MVI}$, moderate visual impairment.

TABLE 4: Principal cause of bilateral blindness and bilateral visual impairment with available correction (presenting visual acuity).

\begin{tabular}{|c|c|c|c|c|c|c|}
\hline \multirow[t]{2}{*}{ Variable } & \multicolumn{2}{|c|}{ Blindness $\uparrow(n=62)$} & \multicolumn{2}{|c|}{ Severe visual impairment $\div(n=41)$} & \multicolumn{2}{|c|}{ Moderate visual impairment $\S(n=149)$} \\
\hline & $n$ & $\%$ & $n$ & $\%$ & $n$ & $\%$ \\
\hline 1. Refractive error & 3 & 4.8 & 13 & 31.7 & 93 & 62.4 \\
\hline 2. Cataract, untreated & 35 & 56.5 & 14 & 34.1 & 39 & 26.2 \\
\hline 3. Aphakia uncorrected & 0 & 0.0 & 0 & 0.0 & 0 & 0.0 \\
\hline 4. Cataract surgical complications & 2 & 3.2 & 1 & 2.4 & 0 & 0.0 \\
\hline 5. Trachomatous corneal opacity & 1 & 1.6 & 0 & 0.0 & 0 & 0.0 \\
\hline 6. Non-trachomatous corneal opacity & 2 & 3.2 & 2 & 4.9 & 0 & 0.0 \\
\hline 7. Glaucoma & 9 & 14.5 & 3 & 7.3 & 4 & 2.7 \\
\hline 8. Diabetic retinopathy & 0 & 0.0 & 0 & 0.0 & 1 & 0.7 \\
\hline 9. ARMD & 2 & 3.2 & 5 & 12.2 & 5 & 3.4 \\
\hline 10. Other posterior segment disease & 6 & 9.7 & 3 & 7.3 & 5 & 3.4 \\
\hline 11. Other globe/CNS abnormalities & 2 & 3.2 & 0 & 0.0 & 2 & 1.3 \\
\hline Total & 62 & 100.0 & 41 & 100.0 & 149 & 100.0 \\
\hline A. Total classified as treatable $(1,2,3)$ & 38 & 61.3 & 27 & 65.9 & 132 & 88.6 \\
\hline C. Preventable (ophthalmic services) $(4,7,8)$ & 11 & 17.7 & 4 & 9.8 & 5 & 3.4 \\
\hline D. Total avoidable blindness $(A+B+C)$ & 52 & 83.9 & 33 & 80.5 & 137 & 92.0 \\
\hline E. Posterior segment causes $(7,8,9,10)$ & 17 & 27.4 & 11 & 26.8 & 15 & 10.1 \\
\hline
\end{tabular}

$A M D$, age-related macular degeneration; $C N S$, central nervous system; $\mathrm{PHC}$, primary healthcare; $\mathrm{PEC}$, primary eye care.

$\dagger$, Visual acuity $<3 / 60 ; \ddagger$, Visual acuity $<6 / 60$ and $>3 / 60)$; $\S$, Visual acuity $<6 / 18$ and $>6 / 60$ ).

TABLE 5: Age- and sex-adjusted prevalence of different levels of visual impairment in eyes with cataract in people aged >50 years in Rwanda (2015)

\begin{tabular}{|c|c|c|c|c|c|c|c|c|c|}
\hline \multirow{2}{*}{$\begin{array}{l}\text { Visual acuity } \\
\text { level }\end{array}$} & \multicolumn{3}{|c|}{ Males } & \multicolumn{3}{|c|}{ Females } & \multicolumn{3}{|c|}{ Total } \\
\hline & $\begin{array}{l}\text { Projected number } \\
\text { of eyes }(n)\end{array}$ & $\%$ & $95 \% \mathrm{Cl}$ & $\begin{array}{l}\text { Projected number } \\
\text { of eyes }(n)\end{array}$ & $\%$ & $95 \% \mathrm{Cl}$ & $\begin{array}{l}\text { Projected number } \\
\text { of eyes }(n)\end{array}$ & $\%$ & $95 \% \mathrm{Cl}$ \\
\hline \multicolumn{10}{|c|}{ Cataract and VA $<3 / 60$ with best correction or pinhole } \\
\hline Cataract eyes & 9525 & 1.0 & $0.7-1.4$ & 17349 & 1.4 & $1.0-1.8$ & 26874 & 1.2 & $0.9-1.5$ \\
\hline \multicolumn{10}{|c|}{ Cataract and VA $<6 / 60$ with best correction or pinhole } \\
\hline Cataract eyes & 11904 & 1.3 & $0.8-1.7$ & 20762 & 1.7 & $1.2-2.1$ & 32666 & 1.5 & $1.1-1.9$ \\
\hline \multicolumn{10}{|c|}{ Cataract and VA $<6 / 18$ with best correction or pinhole } \\
\hline
\end{tabular}

VA, visual acuity; $\mathrm{Cl}$, confidence interval. 
TABLE 6: Cataract surgical coverage.

\begin{tabular}{|c|c|c|c|c|c|c|c|c|c|}
\hline \multirow{2}{*}{$\begin{array}{l}\text { Visual acuity } \\
\text { threshold }\end{array}$} & \multicolumn{3}{|c|}{ Cataract surgical coverage (persons) (\%) } & \multicolumn{3}{|c|}{ Cataract surgical coverage (eyes) (\%) } & \multicolumn{3}{|c|}{  } \\
\hline & Males & Females & Total & Males & Females & Total & Males & Females & Total \\
\hline$V A<3 / 60$ & 69.2 & 67.9 & 68.4 & 52.1 & 48.2 & 49.5 & 53.9 & 54.7 & 54.4 \\
\hline$V A<6 / 60$ & 56.3 & 64.4 & 61.5 & 46.2 & 43.6 & 44.5 & 43.8 & 52.5 & 49.5 \\
\hline$V A<6 / 18$ & 46.3 & 42.9 & 43.9 & 39.5 & 32.1 & 34.3 & 36.6 & 32.7 & 33.8 \\
\hline
\end{tabular}

$\mathrm{VA}$, visual acuity.

TABLE 7: Outcome after cataract surgery with available correction (eyes).

\begin{tabular}{lcccccccc}
\hline \multirow{2}{*}{$\begin{array}{l}\text { Toperative visual acuity } \\
\text { threshold }\end{array}$} & \multicolumn{2}{c}{ Males } & & \multicolumn{2}{c}{ Females } & & \multicolumn{2}{c}{ Total } \\
\cline { 2 - 3 } & $\boldsymbol{n}$ & $\mathbf{\%}$ & & $\boldsymbol{n}$ & $\mathbf{\%}$ & & $\boldsymbol{n}$ & $\mathbf{\%}$ \\
\hline Good: can see 6/18 & 37 & 75.5 & & 63 & 68.5 & & 100 & 70.9 \\
Borderline: can see 6/60 & 6 & 12.2 & & 13 & 14.1 & & 19 & 13.5 \\
Poor: cannot see 6/60 & 6 & 12.2 & & 16 & 17.4 & & 22 & 15.6 \\
\hline Total & $\mathbf{4 9}$ & $\mathbf{1 0 0 . 0}$ & & $\mathbf{9 2}$ & $\mathbf{1 0 0 . 0}$ & $\mathbf{1 4 1}$ & $\mathbf{1 0 0 . 0}$ \\
\hline
\end{tabular}

outcome uncorrected (VA < 6/60); with correction, this figure fell to $12.8 \%$. The most common cause of a poor outcome after surgery was refractive errors (31.7\% of cases) followed by comorbidity (26.8\%).

Those who were bilaterally blind (VA $<6 / 60$ ) because of cataract were asked why they had not undergone surgery $(n=51)$, and the answers varied by gender: for men, the most common reason was a lack of awareness that treatment was possible $(31.6 \%)$, whilst for women it was difficult to reach the hospital $(40.6 \%)$. Affordability was also an issue for both the insured and uninsured, with $10.5 \%$ of uninsured men and $12.5 \%$ of uninsured women citing cost as a barrier; and an additional $10.5 \%$ of men and $9.4 \%$ of women with insurance also saying that they could not afford surgery. A total of $97.1 \%$ of operated eyes $(137 / 141)$ had an intraocular lens inserted during the cataract procedure.

The total prevalence of refractive error (excluding presbyopia) in the population was $4.3 \%$, half of which was uncorrected $(2.2 \%)$. However, the majority of the population reported uncorrected presbyopia (89.9\%).

This RAAB included an additional question that was deemed important by planners for the local context. Respondents were asked whether they were aware of the availability of eye tests and treatments (primary eye-care [PEC] services) at the local health centre, to which $57 \%$ of respondents replied that knew of the service (no significant difference between the sexes).

Finally, the results from the 2006 RAAB conducted in the Western province ${ }^{11}$ were compared to the results from the current survey to identify trends in eye health and service provision (see Table 8). The results showed a downward trend in the prevalence of blindness, improved CSC and improved outcomes of cataract surgery.

Cataract remained the leading cause of blindness (although with a reduced percentage).
TABLE 8: Trends in eye-care data between two surveys nine (9) years apart.

\begin{tabular}{|c|c|c|c|c|}
\hline Item & $\begin{array}{l}2006 \text { Western } \\
\text { province }\end{array}$ & $\begin{array}{l}2015 \text { Western } \\
\text { province }\end{array}$ & $\begin{array}{c}2015 \\
\text { Nationwide }\end{array}$ & 9-year trend \\
\hline Number examined & 2250 & 1317 & 5275 & \\
\hline \multicolumn{5}{|l|}{ Prevalence } \\
\hline \multicolumn{5}{|l|}{ Blindness } \\
\hline Prevalence & 1.6 & 0.8 & 1.1 & \\
\hline $95 \% \mathrm{Cl}$ & $1.0-2.2$ & $0.3-1.3$ & $0.7-1.4$ & \\
\hline \multicolumn{5}{|l|}{ SVI } \\
\hline Prevalence & 1.1 & 0.6 & 0.7 & \multirow{5}{*}{$\begin{array}{l}\text { Reducing } \\
\text { prevalence of } \\
\text { blindness }\end{array}$} \\
\hline $95 \% \mathrm{Cl}$ & $0.7-1.6$ & $0.2-1.0$ & $0.5-1.0$ & \\
\hline MVI & & & & \\
\hline Prevalence & 4.9 & 2.5 & 2.6 & \\
\hline $95 \% \mathrm{Cl}$ & $3.8-6.0$ & $1.4-3.5$ & $2.1-3.2$ & \\
\hline \multicolumn{5}{|l|}{$\begin{array}{l}\text { Cataract surgical } \\
\text { coverage }\end{array}$} \\
\hline Total $(\%)$ & 47.2 & - & 68.4 & \multirow{3}{*}{$\begin{array}{l}\text { - Improved } \\
\text { coverage } \\
\text { - Closing } \\
\text { gender gap }\end{array}$} \\
\hline Male (\%) & 64.3 & - & 69.2 & \\
\hline Female $(\%)$ & 36.5 & $54.5 \dagger$ & 67.9 & \\
\hline \multicolumn{5}{|l|}{$\begin{array}{l}\text { Outcomes of } \\
\text { surgery }\end{array}$} \\
\hline Good (\%) & 24 & 73.7 & 70.9 & \multirow{3}{*}{$\begin{array}{l}\text { Improving } \\
\text { outcomes of } \\
\text { cataract surgery }\end{array}$} \\
\hline Borderline (\%) & 35 & 15.8 & 13.5 & \\
\hline Poor (\%) & 41 & 10.5 & 15.6 & \\
\hline \multicolumn{4}{|l|}{$\begin{array}{l}\text { Leading cause of } \\
\text { blindness }\end{array}$} & \multirow{2}{*}{$\begin{array}{l}\text { Cataract still } \\
\text { the leading } \\
\text { cause but lower } \\
\text { fraction }\end{array}$} \\
\hline Cataract (\%) & 65.0 & 54.5 & 56.5 & \\
\hline
\end{tabular}

SVI, severe visual impairment; MVI, moderate visual impairment.

$\dagger$, Sex-disaggregated data not available.

\section{Rwanda case study: Using Rapid Assessment of Avoidable Blindness data to influence policy change Background}

Despite ever-increasing investment in eye research programmes in Africa by donors, little is understood about whether this research evidence is being used to inform the development of context-specific policies, including pro-poor policies to improve eye health. Policy here is loosely defined as a course of action, an action on the ground, a plan or a declaration. This loose definition has been adapted in other studies. ${ }^{15}$ Some researchers have advocated for widespread data from multiple sources to inform policy and practice, which can not only contribute to universal eye health but also promote universal health coverage (UHC). ${ }^{16}$

Rwanda became a signatory of 'VISION 2020: The Right to Sight' in 2012. Since then, Rwanda has developed and implemented three plans of action to eliminate avoidable blindness and visual impairment. The fourth National Strategic Plan for Eye Health (NSPEH: 2018-2024) ${ }^{17}$ has 
been developed in accordance with the current Health Sector Policy and of the fourth Health Sector Strategic Plan (HSSP IV 2018-2024). ${ }^{18}$ This inclusion into the HSSP is a major integration success that saw the $\mathrm{MOH}$ take the lead in drafting of the eye sector plan. Strong leadership has facilitated the successful organisation of eye-care services and collaboration between stakeholders in Rwanda. ${ }^{19}$ For the past five years, eye conditions have been amongst the most important causes of morbidity and are amongst the top ten causes of consultations at primary and secondary levels of the healthcare system. ${ }^{20}$ Primary eye care is considered a key component in the quest for UHC. When an assessment of the existing PEC programmes revealed gaps in the competency of general health workers in PEC and their ability to accurately identify and refer patients with eye complaints, ${ }^{21,22}$ the $\mathrm{MOH}$ determined the requirement of a better programme. This led to the development of a national curriculum for PEC in Rwanda between 2012 and 2013, which was adapted from the WHO PEC Manual. ${ }^{23}$

Planning for eye care is carried out based on expert opinions from members of the professional societies for both ophthalmologists and allied eye health professionals, ${ }^{24}$ research data and data from health information systems. In Rwanda, this is collated and corroborated by the Eye Health Technical Working Group, a body constituted by the $\mathrm{MOH}$.

Following the conclusion of the 2015 RAAB study (results outlined earlier in this paper), the following steps were taken to facilitate the adoption of this evidence by policymakers:

- The RAAB report was sent to the $\mathrm{MOH}$ within one month of completing the survey, including a PowerPoint version of the same.

- The RAAB lay report was produced in language that could be understood by the lawmakers. This report included a section on implications for practice and policy.

- A result dissemination workshop was hosted by the Eye Health Technical Working Group with policymakers from various sectors in attendance.

\section{Impact on policy and practice}

\section{Rapid Assessment of Avoidable Blindness result 1}

The age- and sex-adjusted prevalence of blindness was $1.1 \%(0.7-1.4)$ of which $83.9 \%$ was avoidable, with cataract being the major cause. The CSC was $68.4 \%$ with $51 \%$ of surgeries carried out in referral hospitals. Without correction, $70.9 \%$ of all operated eyes had good vision and $15.6 \%$ had a poor outcome. Difficulty in reaching surgical facilities (33.3\%) was the main barrier to surgery.
The age- and sex-adjusted prevalence of cataract showed a total of 49464 eyes in people aged 50 years and over needing cataract surgery, in the country.

\section{Lay interpretation of the result}

About $4.4 \%$ of Rwandans aged 50 and more have poor vision with $1.1 \%$ being blind. The majority are affected by diseases that can be treated or where blindness could have been prevented. The key cause is cataract, but most people have to travel to referral hospitals to undergo surgery and not everyone has access to cataract surgery services, with many complaining of the distance they have to travel to undergo surgery.

\section{Changes made in policy and practice}

In order to increase cataract surgery services in the country:

- The Eye Health Technical Working Group recommended a new cataract strategy managed by the Rwanda Ophthalmology Society such that every district hospital in the country had a surgeon supporting cataract services. Every ophthalmologist in Rwanda participated in this initiative. This reduced distance as a barrier to access of care and increased the coverage of surgery. This initiative is ongoing.

- The Medical Production, Procurement and Distribution Division $^{25}$ of the Rwanda Biomedical Services was mandated to stock consumables for eye services including cataract surgery. Professionals were tasked with providing a list to the body, so that the consumables could be included in procurement tender processes. In the interim, one partner of the $\mathrm{MOH}$ provided all the consumables needed for cataract surgery across the whole country, and one private supplier began providing cost-effective supplies within Rwanda.

- A policy of bonding ophthalmologists to ensure they serve under the $\mathrm{MOH}$ in the public sector for four years after training was enforced and strengthened to increase the number of surgeons in public service.

- For the first time since the performance-based financing $(\mathrm{PBF})^{26}$ was introduced in Rwanda, PBF indicators for identification of cataract and cataract surgery provision at district hospitals were defined and funded in 2019. Indicators have also been included for eye screenings and treatments in the primary-level health facilities.

- The $\mathrm{MOH}$ recommended local training of ophthalmologists and supported the first local residency programme at the Rwanda International Institute of Ophthalmology. ${ }^{27}$

- The HSSP IV ${ }^{28}$ for the first time included indicators for eye care as part of the UHC package and recommended a sub-sector plan for eye health. The development of this plan, the National Strategic Plan for Eye Health 2018-2024, ${ }^{17}$ was led by the $\mathrm{MOH}$ and is fully integrated with other plans at the ministry. 


\section{Rapid Assessment of Avoidable Blindness result 2}

The prevalence of all refractive errors was $4.3 \%$. The prevalence of uncorrected refractive error was 2.3\% in this population. The proportion of uncorrected presbyopia was $89.9 \%$.

\section{Lay interpretation of the result}

Four to five people out of every 100 aged 50 years and older need distance vision glasses in this population. The majority of the population need reading glasses. Of those needing reading glasses, only $10 \%$ have them, whilst of those needing distance vision glasses, only $50 \%$ have them.

\section{Changes in policy and practice}

In order to improve the refractive error correction services in the country:

- The programme of supplying ready-made reading glasses to every health centre in the country as part of the PEC programme was strengthened by holding stock at the Medical Procurement and Distribution Division, which in turn supplied the district pharmacies as a part of the essential drugs that health centres needed. Work is underway to put the glasses on community insurance tariffs.

- Based on a successful pilot of including an optical shop in a provincial hospital, the vision centre project (supported by a partner organisation) was adopted and expanded to cover each and every district hospital. These optical shops provide glasses at low cost to the population referred from the health centres. The eye health professionals based at district hospitals received refresher training on refraction.

- The first optical workshop in the country was opened at the University of Rwanda to supply spectacles to the district hospitals. At district hospitals' optic shops patients select frames. The design number as well as the prescription is electronically sent to the workshop and then finished spectacles are sent back to the hospital using public transport courier services.

\section{Rapid Assessment of Avoidable Blindness result 3}

Glaucoma (14.5\%), age-related macular degeneration (3.2\%) and other posterior segment conditions (9.7\%) constituted $27.4 \%$ of all blindness.

\section{Lay interpretation of the result}

Diseases affecting the back of the eye were becoming more prevalent as the causes of blindness.

\section{Change in policy and practice}

A revision of packages of activities and tariffs was carried out; and for the first time, insurance companies included specific tariffs for reimbursement of diagnostic or curative procedures for posterior segment procedures such as laser therapy, optical coherence tomography, vitreoretinal surgery, consumables and glaucoma shunts. This is operational in private hospitals and private insurance schemes and is in progress for the public hospitals and community insurance schemes.

\section{Factors for success in impacting policy}

An analysis was made of the approaches used in engaging with policy and practice using the RAAB results. The findings are presented below against the key areas identified in the The Overseas Development Institute Research and Policy in International Development (ODI RAPID) framework ${ }^{29}$ (see Figure 1).

\section{External influences and policy context}

The linkage between improved vision and the development agenda and global prosperity is reflected through the sustainable development goals, in particular, goals 1, 3, 4, 5, 8, 10 and 17. Achievement of these goals additionally requires increased government interest in eye care..$^{30,31}$

Rwanda is one of the successes in relation to UHC, which was attained in Rwanda because of the leadership that believes in good health as a fundamental human right, and a population that has embraced the Community-Based Health Insurance scheme at a rate of $91 \%$ coverage. ${ }^{32}$ Eye health has been included and supported by the $\mathrm{MOH}$ as a key component of both UHC and the non-communicable disease agenda.

Three principles guided change in the delivery of eye care in Rwanda: (1) prioritising geographic equity of service delivery, (2) reducing the cost of access to services and (3) coordinating all partners under a single national plan. ${ }^{19}$ This led to the launching of a comprehensive PEC programme in 2010. This programme includes creating a permanent PEC curriculum at all eight nursing schools in Rwanda, which has resulted in educating 1250 existing health centre nurses in the PEC services and improving the referral guidance.

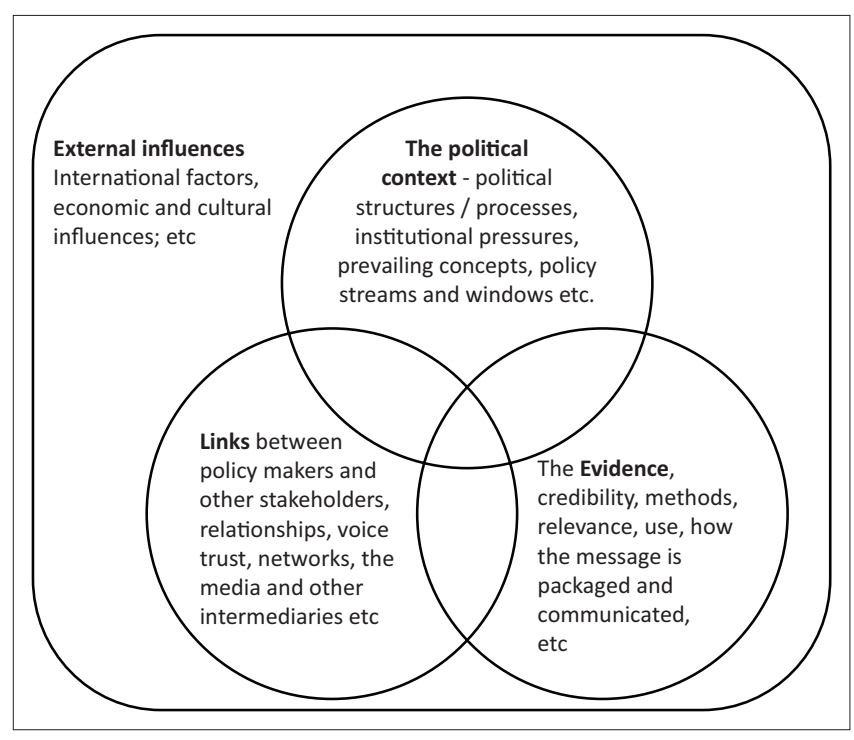

FIGURE 1: The ODI RAPID Framework for research to policy. 
Within this policy and service provision context, reform based on RAAB evidence was able to drive systemic change, including an increase in community and health worker's awareness regarding cataract services at the primary level, and improved referral patterns to district hospitals under the PEC programme. The success and government support for the PBF programme ${ }^{33}$ also made it feasible to add indicators for eye health into the scheme. The PEC programme could be further strengthened to distribute reading glasses.

\section{Evidence}

When evidence is credible and convincing, provides practical solutions to the pressing policy problems and is packaged to attract policymakers' interest, it is more likely to be accepted by policymakers. The RAAB is a standardised populationbased survey which generates not only prevalence data but also service indicators including CSC and cataract surgical outcome. The methodology has been used in over 330 surveys across 70 countries worldwide, providing a substantial contribution of data used to calculate global blindness estimate assessment and provide data to inform eye-care programmes and policies with the aim of reducing or eliminating avoidable blindness. ${ }^{5}$ Data from the Rwanda $\mathrm{RAAB}$ were robust and credible; and for policymakers, the fact that it was nationwide was very important. The survey was conducted and supervised by a certified trainer as recommended for quality control, and the data analyses were reviewed by an international reviewer before reports were generated.

Production of lay reports in simple language allowed policymakers to clearly understand the data. Ethics and scientific review guidelines in Rwanda include a clear dissemination strategy in the proposal. ${ }^{34}$ The mandatory dissemination workshops allowed wide sharing of data with stakeholders and policymakers.

\section{Links}

The Eye Health Technical Working group for eye health is headed by the Director of Planning at the $\mathrm{MOH}$.

It is a forum that allows ophthalmologists, researchers and policymakers to share common networks, develop trust and effectively communicate. New ideas that impact eye health and challenges facing eye health are first discussed in this forum. Both the scientific and lay reports and the recommendations from the RAAB were first presented to this group. The leadership structure of the committee allows quick transmission of information and proposals for policy change to the policymakers.

\section{Case study conclusion}

Evidence is essential to inform national eye-care plans. Many low- and middle-income countries use these plans to guide efforts to strengthen the eye-care services. Advocates of scientific evidence need to clearly communicate findings and tell compelling stories to grab the attention and appeal to the emotions of policymakers. ${ }^{35}$

Improving how RAAB data are communicated, identifying key political opportunities that the data support and developing linkages with policymakers have helped the evidence from the 2015 RAAB inform specific policy and practice changes in Rwanda.

\section{Discussion}

This is the first nationwide population-based study on the prevalence and causes of blindness conducted in Rwanda. The age- and sex-adjusted prevalence of blindness and visual impairment in those aged 50 years and more was $1.1 \%$ (CI $0.7-1.4$ ), which is lower (although the difference is not statistically significant) than the initial estimate based on a previous provincial RAAB in Rwanda, ${ }^{11}$ where the prevalence was $1.6 \%$ (CI 1.0-2.2). Most of the causes of blindness (83.9\%) and visual impairment $(92.0 \%)$ are avoidable.

Extrapolations based on the age- and sex-adjusted results suggested that 48286 people were either blind or vision impaired, in Rwanda, with 11594 expected to be blind and 36692 expected to be visually impaired. As this is a national data, it can be used to set targets for interventions including cataract surgery.

The leading cause of blindness is still cataract (56.5\%), an agerelated clouding of the lens in the eye, whilst the second leading cause was glaucomatous optic atrophy. The main cause of visual impairment (VA $<6 / 18-6 / 60)$ was refractive errors. The proportion of blindness because of cataract has reduced compared to the previous 2006 province-level survey (65.0\% of blindness in 2006), which could be attributed to higher CSC, which increased from $47.2 \%$ in the previous $\mathrm{RAAB}^{11}$ to $68.4 \%$ in this survey (at the $<3 / 60$ level). The CSC was similar amongst men and women. Given that CSC varies according to the level of VA used to indicate surgery, it is promising to see a coverage of $49.5 \%$ at the $<6 / 18$ level in this survey, which is even higher than the $21.4 \%$ coverage at $<6 / 60$ recorded in the previous survey. ${ }^{11}$

The high proportion of blindness because of cataract can be attributed to Rwanda's low cataract surgical rate (CSR), which is estimated to still be below 500 surgeries per million people per year. Work by Lewallen et al. estimated the CSR required to eliminate visual impairment because of cataract in African countries. ${ }^{36}$ The ideal CSR to eliminate all blinding cataract in Rwanda was 1000 surgeries per million people, and to eliminate all visually impairing cataracts was 1800 surgeries per million people. Considerable scope is still available for improvement in surgical numbers in Rwanda. It was, however, encouraging to note that almost half of the cataract surgeries had been carried out in district hospital, as this demonstrates that services have moved closer to the people. 
This RAAB survey recorded a marked improvement in cataract surgical outcomes, with $70.9 \%$ presenting with good outcomes compared to just $24 \%$ in the previous provincial survey. Specific actions taken by ophthalmology programmes after the first RAAB, such as vetting of visiting surgeons, better selection of training programmes for Rwandan ophthalmologists and increased investment in eye care by the government, have contributed to these improvements. Nevertheless, there is still space for improvement: $13.5 \%$ of eyes were classified as 'borderline', and $15.6 \%$ as 'poor', which is higher than the WHO's recommendations of $<5 \%$ poor outcomes. ${ }^{37}$ Surgical complications contributed to $41 \%$ of poor outcomes, whilst refraction (63\%) was the main cause of the borderline results. Review of surgical procedures and competencies, and routine monitoring of cataract surgical outcome may help reduce the poor outcomes, whilst good biometry and provision of glasses is likely to reduce borderline post-surgical visual outcome considerably. It would also be useful to calculate the eCSC which is the UHC indicator that combines a coverage measure (CSC) with quality (postoperative visual outcome). ${ }^{14}$ This is especially important, as the quality of surgery and the resulting patient satisfaction can be the engines that drive sustainable cataract services. ${ }^{38}$

Even though the prevalence of refractive errors (excluding presbyopia) in this population is not high $(4.3 \%)$, half of the people with refractive error in this survey had no correction, whilst a large proportion of presbyopia (89.9\%) were uncorrected, demonstrating an unmet need for glasses in the Rwandan population. Specific programmes to ensure glasses are available across the country are in place, but it is still too early for their impact to be felt, as for several years, glasses were only available in large towns.

Sixteen percent of those with poor vision require low-vision services and/or rehabilitation. These are people who despite all treatments, operations and medication at our disposal cannot have their sight improved. At the time of writing this article, Rwanda had no low-vision specialist and only one rehabilitation service. These services need to be included in planning.

Just over half of the population were aware that they could receive an eye check-up within their sector (within $5 \mathrm{~km}$ of their home). As PEC trained nurses are now available at every health centre, further increasing the awareness of this service will improve the accessibility of eye health services for those who need them. The programme evaluation demonstrated that there has been significant progress in the strengthening of the eye health system and integration of PEC in Rwanda. ${ }^{39}$ Another recent survey of PEC service utilisation showed that nearly one-third of the population in Rwanda have the potential to benefit from PEC, with greater need identified in older people and women. ${ }^{40}$

\section{Conclusion}

Rwanda is one of the first countries in the East and Central Africa region to carry out a nationwide population-based study on the prevalence and causes of blindness. The prevalence of blindness shows a downward trend compared to the previous estimates, but a large proportion of it is still because of the avoidable causes. Cataract remains the leading cause of blindness, whilst refractive errors cause most of the non-blinding visual impairment. Comparison with a 2006 survey showed significant gains in cataract surgery coverage and outcomes, but there is still room for improvement. The political context, the strength of the evidence and the links between stakeholders allowed the data from the RAAB survey to inform specific changes in practice and policy. Results from this survey will continue to inform the design of more targeted and effective interventions, with the aim of improving both the number and the quality of cataract surgery, and improving the provision of refractive services leading to better visual outcomes and quality of life for all Rwandans.

\section{Acknowledgements}

The authors thank the Fred Hollows Foundation and their Rwanda team - specifically Mr David Gasatura and Mr Massimo Presente - for their financial support for the RAAB survey. The authors also thank the survey officers and data team: Mr Damien Kanture, Ms Frida Ntwaza, Mr Innocent Tuyisenge, Mr Regis Twiringirimana, Mr Fulgence Ntakirutimana, Ms Kelly Kwizera, Mr Fabrice Nduwimana, Mr Dieudonne Shida and Mr Colin Mulindwa.

\section{Competing interests}

The authors declare that they have no financial or personal relationships that may have inappropriately influenced them in writing this article.

\section{Authors' contributions}

W.C.M, E.G., A.N., E.B., A.I. and T.H. were responsible for training, conception and design of the study protocol. E.G., A.N., E.B. and A.I. were responsible for performing the field experiments. W.C.M., J.N. and T.H. monitored the study implementation. W.C.M. analysed and cleaned the data. W.C.M. and T.H. drafted the article or revised it critically for important intellectual content. W.C.M., J.N. and P.U. did final approval of the version to be published.

\section{Funding information}

The field costs for this work were funded by the Fred Hollows Foundation.

\section{Data availability}

The RAAB data used in this study is available in the RAAB repository https:/ / raabdata.info/repository/.

\section{Disclaimer}

The funding sources had no role in the design and conduct of the study. The views and opinions expressed 
in this article are those of the authors and not necessarily of the affiliated agencies.

\section{References}

1. Bourne RR, Flaxman SR, Braithwaite $T$, et al. Magnitude, temporal trends, and projections of the global prevalence of blindness and distance and near vision impairment: A systematic review. Lancet Glob Health. 2017;5(9):e888-e897.

2. Resnikoff $S$, Pararajasegaram R. Blindness prevention: Past, present, and future. Bull World Health Organ. 2001;79(3):222-226.

3. Kuper H, Polack S, Limburg H. Rapid assessment of avoidable blindness. Community Eye Health. 2006;19(60):68-69.

4. Mathenge $\mathrm{W}$, Bastawrous A, Foster A, Kuper $\mathrm{H}$. The Nakuru posterior segment eye disease study: Methods and prevalence of blindness and visual impairment in Nakuru, Kenya. Ophthalmology. 2012;119(10):2033-2039. https://doi. org/10.1016/j.ophtha.2012.04.019

5. Mactaggart I, Wallace S, Ramke J, et al. Rapid assessment of avoidable blindness for health service planning. Bull World Health Organ. 2018;96(1):726-728. https://doi.org/10.2471/BLT.18.217794

6. Mullen, Edward J. Evidence-based policy and social work in health and mental health. Soc Work Ment Health. 2008;7(1-3):255-270. https://doi. org/10.1080/15332980802072595

7. Flaxman SR, Bourne RR, Resnikoff $S$, et al. Global causes of blindness and distance vision impairment 1990-2020: A systematic review and meta-analysis. Lance Glob Health. 2017;5(12):e1221-1234.

8. Mactaggart I, Limburg H, Bastawrous A, Burton MJ, Kuper H. Rapid Assessment of Avoidable Blindness: Looking back, looking forward. $\mathrm{Br} J$ Ophthalmol. 2019;103(11):1549-1552. https://doi.org/10.1136/bjophthalmol-2019-314015

9. Kandeke L, Mathenge W, Giramahoro C, et al. Rapid Assessment of Avoidable Blindness in Two Northern Provinces of Burundi without eye services. Ophthalmic Epidemiol. 2012;19(4):211-215. https://doi.org/10.3109/09286586.2012.690493

10. Kikara S. RAAB in Hoima. s.l.: Sight Savers Uganda Country Office; 2013.

11. Mathenge W, Nkurikiye J, Limburg $\mathrm{H}$, Kuper $\mathrm{H}$. Rapid assessment of avoidable blindness in Western Rwanda: Blindness in a post conflict setting. PLoS Med. 2007;4(7):e217. https://doi.org/10.1371/journal.pmed.0040217

12. National Institute of Statistics of Rwanda. Rwanda Population and Household Survey [homepage on the Internet]. 2012 [2021 Mar 31]. Available from: http://statistics. [homepage on the Internet]. 2012 [2021 Mar 31]. Available from: http://sta
gov.rw/system/files/user_uploads/files/books/2012_Census_Final_Draft.pdf

13. WHO. WHO change the definition of blindness [homepage on the Internet]. [cited 2021 Mar 31]. Available from: http://www.who.int/blindness/Change $\% 20$ the $\% 20$ Definition $\% 20$ of $\% 20$ Blindness.pdf

14. Ramke J, Gilbert CE, Lee AC, Ackland P, Limburg H, Foster A. Effective cataract surgical coverage: An indicator for measuring quality-of-care in the context of Universal Health Coverage. PLoS One. 2017;12(3):e0172342. https://doi. org/10.1371/journal.pone.0172342

15. Theobald, S, Taegtmeyer, M, Squire, S, et al. Towards building equitable health systems in Sub-Saharan Africa: Lessons from case studies on operational research. Health research policy and systems. BioMed Central. 2009;7(1):26. https://doi. org/10.1186/1478-4505-7-26

16. Ramke J, Zwi AB, Silva JC, et al. Evidence for universal eye health plans. Bull World Health Organ. 2018;96(10):695-704. https://doi.org/10.2471/BLT.18.213686

17. Rwanda, Ministry of Health. National strategic plan for eye health [homepage on the Internet]. 2018 [cited 2021 Jun 25]. Available from: https://www.moh.gov.rw/ fileadmin/Publications/Strategic_Plan/FINAL_Eye_Care_SP.pdf

18. Ministry of Health Rwanda. Rwanda Fourth Health Sector Strategic Plan (July 2018-June 2024) [homepage on the Internet]. [cited 2021 Jun 25]. Available from: http://moh.gov.rw/fileadmin/templates/Docs/FINALH_2-1.pdf

19. Binagwaho A, Scott K, Rosewall T, et al. Improving eye care in Rwanda Bull World Health Organ. 2015;93(6):429-434. https://doi.org/10.2471/BLT.14.143149

20. Rwanda, Ministry of health. Rwanda health managemnet information systems. s.l.: 2015-2019. Rwanda Ministry of Health; 2019.

21. Courtright $P$, Murenzi J, Mathenge $W$, Reaching rural Africans with eye care services: Findings from primary eye care approaches in Rubavu District, Rwanda. Tropical Med Int Health. 2010;15(6):692-696. https://doi. org/10.1111/j.1365-3156.2010.02530.x
22. Andriamanjato $\mathrm{H}$, Mathenge $\mathrm{W}$, Kalua $\mathrm{K}$, Courtright $\mathrm{P}$, Lewallen S. Task shifting in primary eye care: How sensitive and specific are common signs and symptoms to predict conditions requiring referral to specialist eye personnel? symptoms to predict conditions requiring referral to specialist eye personnel?
Hum Resour Health. 2014;12(Suppl 1 ):S3. https://doi.org/10.1186/1478Hum Resour

23. World Health Organization - Regional Office forAfrica. WHO Primary Eye Care training manual [homepage on the Internet]. 2018 [cited 2021 Jun 23]. Available from: https://www.afro.who.int/sites/default/files/2018-06/WEB-2835-OMSfrom: https://www.afro.who.int/sites/default/fil

24. Rwanda Minstry of Health. Rwanda Ophthalmology Society and Rwanda Ophthalmic Clinical Officers and Cataract Surgeons Society. [cited 2021 Jun 25]. Available from: http://www.icoph.org/advancing_leadership/ophthalmologic societies/society_detail/001F000000Ir5HIAQ/Rwanda-OphthalmologicalSociety.html

25. Majoro J. Availability of health commodities for public sector in Rwanda: Case study of Medical Production and Procurement Division, MPPD. Masters Thesis. University of Rwanda; December 2016

26. Rwanda, Ministry of Health. Performance Based Financing Procedures Manual for Health Facilities (Hospitals and Health Centers). Rwanda: Ministry of Health; 2018 [cited 2021 Jun 25]. Available from: https://www.moh.gov.rw/ fileadmin/user_upload/Moh/Publications/Guidelines_Protocols/PBF Procedures_Manual_HFs_Final_20181018_last_version_Oct_2018_20181128_ pdf-ilovepdf-compressed.pdf

27. IAPB. Introducing COECSA's new competence based residency at RIIO School of Ophthalmology, Rwanda [homepage on the Internet]. s.l.: Rwanda International Institute of Ophthalmology. [cited 2021 Mar 31]. Avilable from: https://www.iapb. $\mathrm{org} /$ news/introducing-coecsas-new-competence-based-residency--at-riioschool-of-ophthalmology-rwanda/

28. Rwanda, Ministry of Health. Rwanda NSP for Health (2018-2024) [homepage on the Internet]. s.l.; 2018. [cited 2021 Jun 25]. Available from: http://moh.gov.rw/ fileadmin/templates/Docs/FINALH_2-1.pdf

29. Young J. Bridging research and policy in international development: An analytical and practical framework. United Kingdom: Overseas Development Institute (ODI); 2004

30. Haslam D, Trimmel J. Universal Eye Health and the Sustainable Development Goals. s.I. IAPB Vision Atlas; 2016.

31. Khandekar R. Sustainable Developmental Goals (SDGs) and eye health care in Nepal. Nepal J Ophthalmol. 2017;9(18):105-107. https://doi.org/10.3126/ nepjoph.v9i2.19249

32. Woldemichael A, Gurara D, Shimeles A. The impact of community based health insurance schemes on out-of-pocket healthcare spending: Evidence from Rwanda. Washington D.C.: International Monetary Fund (IMF) Working Paper WP/19/38 February 2019.

33. Janssen W, De Dieu Ngirabega J, Matungwa M, Van Bastelaere S. Improving quality through performance-based financing in District Hospitals in Rwanda between 2006 and 2010: A 5-year experience. Trop Doctor. 2015;45(1):27-35. https://doi.org/10.1177/0049475514554481

34. Rwanda Ministry of Health. Guidelines for researchers intending to. s.I.: $\mathrm{MOH}$.

35. Davidson B. Storytelling and evidence-based policy: Lessons from the grey literature. Palgrave Commun. 2017;3:17093. https://doi.org/10.1057/ palcomms.2017.93

36. Lewallen S, Williams TD, Dray A, et al. Estimating incidence of vision-reducing cataract in Africa: A new model with implications for program targets. Arch Opthalmol. 2010;128(12): 1584-1589. https://doi.org/10.1001/archophthalmol. 2010.307

37. Limburg H, Foster A, Vaidyanathan K, Murthy GV.Monitoring visual outcome of cataract surgery in India. Bull World Health Organ. 1999;77(6):455-460.

38. Congdon N, Dodson S, Chan VF, Mathenge W, Moo E. Improving the practice of cataract surgical outcome measurement. Community Eye Health 2019;31(104):91-92

39. Yip JLY, Bright T, Ford $\mathrm{S}$, et al. Process evaluation of a national primary eye care in Rwanda. BMC Health Serv Res. 2018;18:950. https://doi.org/10.1186/s12913018-3718-1

40. Bright T, Kuper H, Macleod D, Musendo D, Irunga P, Yip J. Population need for primary eye care in Rwanda: A national survey. PLOS One. 2018;13(5):e0193817. https://doi.org/10.1371/journal.pone.0193817 